\title{
Induction of a less aggressive phenotype in human colon carcinoma HCT116 cells by chronic exposure to HDAC inhibitor SAHA
}

\author{
ALESSANDRO BRESSAN, MARIO BIGIONI, DANIELA BELLAROSA, FEDERICA NARDELLI, \\ CLELIA IRRISSUTO, CARLO ALBERTO MAGGI and MONICA BINASCHI
}

Department of Pharmacology, Menarini Ricerche, Via Tito Speri 10, Pomezia, Rome, Italy

Received June 23, 2010; Accepted August 13, 2010

DOI: $10.3892 /$ or_00000979

\begin{abstract}
Histone deacetylase inhibitors (HDACis) are anticancer molecules that epigenetically modulate cell functions. Chronic exposure of HCT116 colon cancer cells to SAHA has been investigated for a better understanding of resistance mechanisms but, surprisingly, a less aggressive tumor phenotype both in vitro and in vivo was obtained after exposure to increasing concentrations of SAHA. Indeed, HCT116/SAHA cells when injected into nude mice showed a reduced engraftment and growth with respect to HCT116 cells. This difference was not observed inoculating the cells into NOD/SCID mice that, differently from nude mice, lack NK activity, thus suggesting the involvement of the native immune response in impairment of HCT116/SAHA cell growth. In agreement with this result, a growing induction of NKG2D ligand expression, MICA and MICB, that are molecular mediators of NK cell killing, was confirmed in HCT116/SAHA chronically exposed to SAHA. A reduced clonogenic efficiency was also observed in HCT116/SAHA with respect to HCT116 cells. Interestingly, even after chronic exposure to SAHA, HCT116/SAHA cells developed only a moderate resistance to SAHA both in vitro and in vivo and they acquired a collateral sensitivity to anthracyclines. These results are of note and probably rely on the fact that, having simultaneously many different targets, HDACis would require many different mutations to display high resistance index. Moreover, to understand the molecular basis of HCT116/SAHA cell phenotype a gene expression profile of cancer genes was evaluated in HCT116 incubated with SAHA for $24 \mathrm{~h}$ and in HCT116/SAHA cells to identify selectively regulated genes.
\end{abstract}

Correspondence to: Dr Monica Binaschi, Department of Pharmacology, Menarini Ricerche, Via Tito Speri 10, Pomezia, Rome, Italy

E-mail: mbinaschi@menarini-ricerche.it

Key words: HDAC inhibitor, HCT116 cells, tumorigenic potential, anthracycline sensitivity

\section{Introduction}

HDACis are a new class of anticancer agents. Many HDACis are currently in clinical trials as single agents and also in combination with classical chemotherapy or with biological therapies (1). Zolinza ${ }^{\circledR}$ (Vorinostat, Merck) and Istodax (Gloucester Pharmaceuticals) for the moment, are the only HDACis approved for the treatment of cutaneous T-cell lymphoma (2).

HDACis represent a promising epigenetic treatment for cancer because in preclinical models they show pleiotropic antitumor effects in different tumor histotypes. In the literature many mechanisms of actions have been ascribed to HDACis likely depending on the cell type investigated $(3,4)$. Understanding which mechanism is operating in a certain type of cell is at the basis for a more efficacious and less toxic therapy and should permit the treatment of many tumor histotypes (5). Actually, the activity of HDACis in solid tumors and in major haematologic tumors is an important key point being addressed in many ongoing clinical trials (3). HDAC enzymes play critical roles in many biological processes and each of them shows non-redundant functions $(1,3)$.

HDACs can be divided into two families: the Zn-dependent family composed by class I (HDAC 1,2,3,8), class II (HDAC 4,5,6,7,9,10), class IV (HDAC 11) and the NADdependent SIR enzymes $(1,3)$. The comprehension of which HDAC enzyme is important to be inhibited could lead to better pharmacological activities and also to progress in the cancer therapy using optimal combination and timing schedule. Nevertheless, currently HDACis both approved and in clinical development are mainly pan-inhibitors acting on Zn-dependent family $(1,3)$.

Beside the demonstration of the potential activity in major tumor histotypes, important is to investigate whether HDACis can induce tumor resistance since in patients the drugs are administered daily for long periods.

Thus, HCT116 colon cancer cells were chronically exposed to SAHA. SAHA is an unselective, competitive HDACi that is inserted into the catalytic pocket of the natural substrate. In this study we provide evidence that the chronic inhibition of HDACs through the SAHA molecule induces a less aggressive phenotype of HCT116 colon cancer cells both in vitro and in vivo. 


\section{Materials and methods}

Cell lines, drugs and chemicals. SAHA was synthesized at Chemistry Department of Menarini Ricerche (Pomezia, Rome, Italy). Propidium iodide (PI) was purchased from Sigma (St. Louis, MO, USA) and dissolved in hypotonic buffer $(0.1 \% \mathrm{Na}$ citratum) at the concentration of $50 \mu \mathrm{g} / \mathrm{ml}$. The HCT116 cell line was purchased from the American Type Culture Collection (ATCC), USA. The cells were routinely cultured in standard medium (McCoy's 5A supplemented with $10 \%$ FCS and $2 \mathrm{mM}$ glutamine) (Gibco, $\mathrm{CA}, \mathrm{USA})$ at $37{ }^{\circ} \mathrm{C}$ in a humified atmosphere with $5 \% \mathrm{CO}_{2}$.

Selection of HCT116/SAHA cells. For the treatments of HCT116 with SAHA, the cells were seeded in $25-\mathrm{cm}^{2}$ flasks, at a density of $8 \times 10^{5}$ cells/flask. After overnight incubation, the cells were treated with increasing SAHA concentrations up to $6 \mu \mathrm{M}$ SAHA.

Drug sensitivity assay. Different numbers of HCT116 cells or HCT116/SAHA cells were plated on $35-\mathrm{mm}$ cell culture dishes. After $24 \mathrm{~h}$ SAHA or cytotoxic drugs were added. Cells exposed to SAHA were incubated for 7 days to allow colony formation, instead cells exposed to cytotoxic drugs, after $24 \mathrm{~h}$ of drug incubation, were washed and drug-free medium was added for 7 days. Each experiment was performed at least twice using triplicate samples. $\mathrm{IC}_{50}$ concentrations were obtained plotting the clonogenic survival against drug concentrations.

Real-time PCR assays. Total RNA was prepared according to the procedure of the kit (Promega, CA, USA). cDNAs were synthesized using the 'Reverse Transcription System' kit (Promega) and amplified in the presence of $12.5 \mu 1$ of $2 \mathrm{X}$ TaqMan Universal PCR Master Mix and $1.25 \mu 1$ of $20 \mathrm{X}$ Taqman Gene Expression Assay (Applied Biosystems, CA, USA) to a final volume of $25 \mu \mathrm{l}$. The Taqman Gene Expression Assays were: Hs00741286_m1 for the MHC class I polypeptide-related sequence A (MICA), Hs00792952_m1 for the MHC class I polypeptide-related sequence B (MICB), Hs00360941_m1 for the UL16 binding protein 1 (ULBP1), Hs00225909_m1 for the UL16 binding protein 3 (ULBP3), Hs00373622_m1 for the retinoic acid early transcript 1E (RAET1E), Hs00606262_g1 for HDAC1, Hs00187320_m1 for HDAC 3, Hs00195814_m1 for HDAC 4, Hs00195869_m1 for HDAC 6, Hs00218503_m1 for HDAC 8.

As endogenous control, cDNA samples were amplified in the presence of the 20X Taqman Gene Expression Assay Hs99999904_m1 for the Cyclophilin A (PPIA). After 10 min of incubation at $95^{\circ} \mathrm{C}$ for denaturation, samples were subjected to 45 cycles of PCR. Each cycle was $95^{\circ} \mathrm{C} 15 \mathrm{sec}$ and $60^{\circ} \mathrm{C} 1 \mathrm{~min}$. (7300 Real-Time PCR System, Applied Biosystems).

Tumor gene expression by real-time PCR array. cDNA samples were mixed with $\mathrm{RT}^{2}$ qPCR Master Mix (SuperArray Bioscience Corp., MD, USA). The gene expression analysis was performed in a 96-well $\mathrm{RT}^{2}$ Profiler PCR Array for human cancer (SuperArray Bioscience). In this array, each well contains a primer pair specific for one of 84
Table I. Cytotoxic activity of HDAC inhibitors in HCT116 cells.

\begin{tabular}{ll}
\hline Compounds & $\mathrm{IC}_{50}(\mu \mathrm{M})$ \\
\hline SAHA & 1.2 \\
MS-275 & 0.58 \\
TSA & 0.02 \\
LAQ-824 & 0.05 \\
\hline
\end{tabular}

The cytotoxic activity was performed using Alamar blue assay. HCT116 cells were plated in 96-wells and after $24 \mathrm{~h}$ different HDACis concentrations were added for $96 \mathrm{~h}$.

key genes representative of different pathways involved in human cancer, besides housekeeping genes and control wells. After an initial denaturation at $95^{\circ} \mathrm{C}$ for $10 \mathrm{~min}$, the cycling program was $95^{\circ} \mathrm{C}, 15 \mathrm{sec}$ and $60^{\circ} \mathrm{C}, 1 \mathrm{~min}$ for 40 cycles. Raw data were analyzed with the $\Delta \Delta \mathrm{C}_{\mathrm{t}}$ method. Data from control cells were set as calibrator for the relative quantification.

Tumor xenografts. Female athymic nude and NOD-SCID mice 6-7-weeks old (Charles River, Calco, Lecco, Italy) were used throughout the study. Mice were maintained in microisolator cages and supplied with sterile materials under standard conditions, according to UKCCCR guidelines (6). Human tumor lines HCT116 and HCT116/SAHA originated from s.c. in vivo injection of tumor cells $\left(15 \times 10^{6}\right.$ cells/flank/0.2 ml). Tumor growth was followed by caliper measurement of length and width twice weekly. Tumor volume was calculated using the formula: volume $\left(\right.$ in $\left.\mathrm{mm}^{3}\right)=$ width $^{2} \mathrm{x}$ length/2 (7). Tumor-bearing mice were treated with SAHA at $50 \mathrm{mg} / \mathrm{kg}$ i.v. once daily, 5 days/week, for a total of 10 doses, starting when tumors were $\sim 50 \mathrm{~mm}^{3}$ in volume. SAHA was dissolved in DMSO and diluted before dosing with D5W (Dextrose 5\%) to a final DMSO concentration not superior to $1 \%$ at a dose volume corresponding to $10 \mathrm{ml} / \mathrm{kg}$ body weight. The control group was treated with the vehicle.

\section{Results}

Chronic exposure to SAHA of HCT116 cells. Human colon cancer HCT116 cells are extremely sensitive to HDACis. In Table I the cytotoxic effects of HDACis belonging to different chemical classes are reported in HCT116 cells. SAHA, after $96 \mathrm{~h}$ of incubation, shows an $\mathrm{IC}_{50}$ value of $1.2 \mu \mathrm{M}$. Other cell lines, such as T24 or A549, are generally more resistant to HDACis (data not shown).

Given the good sensitivity of this cell line, the cells were exposed to increasing concentrations of SAHA up to $6 \mu \mathrm{M}$ for about 30 passages. The selection induced a different cell shape, as shown in Fig. 1 (HCT116/SAHA); indeed, cells grown in SAHA containing medium, were larger, more vacuolated and presenting pseudopodes. Moreover, HCT116/ 


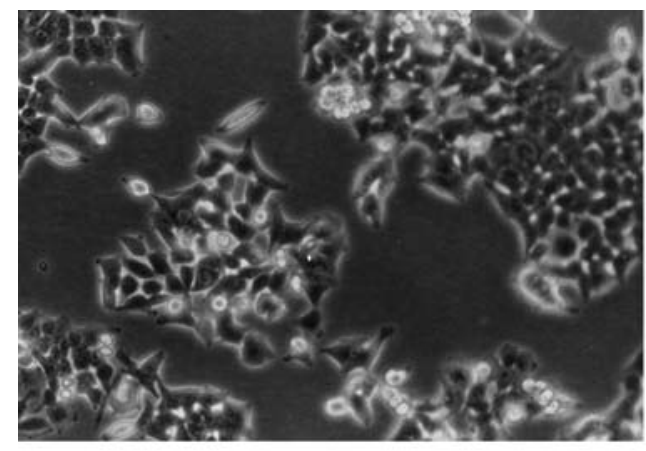

HCT116 wt

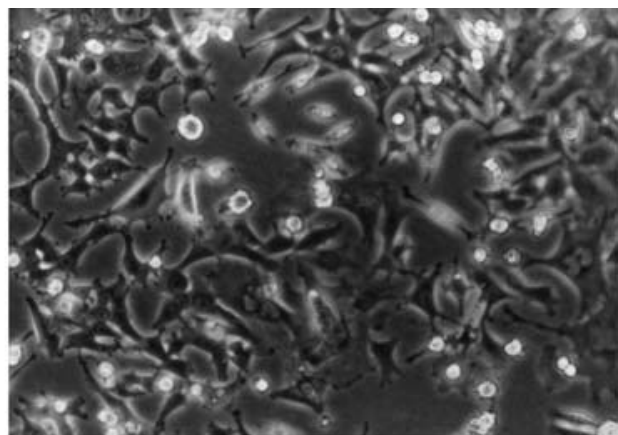

HCT116 / SAHA

Figure 1. Morphology of HCT116/SAHA cells.

A

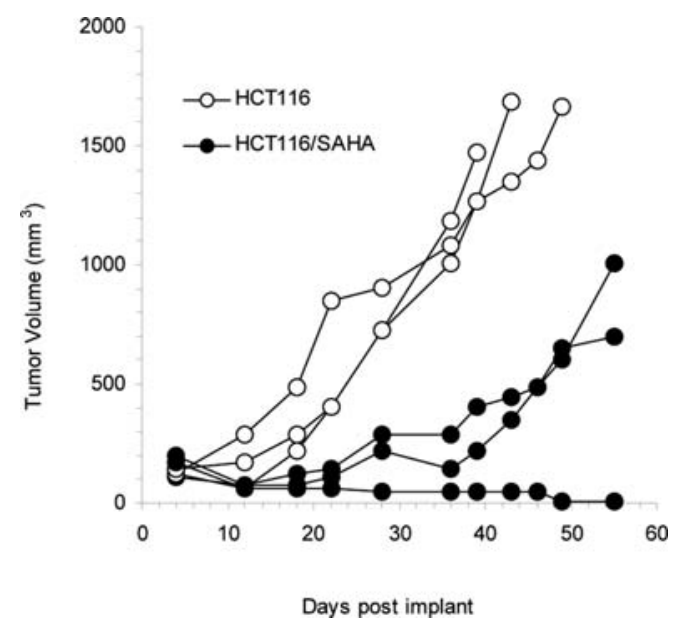

B

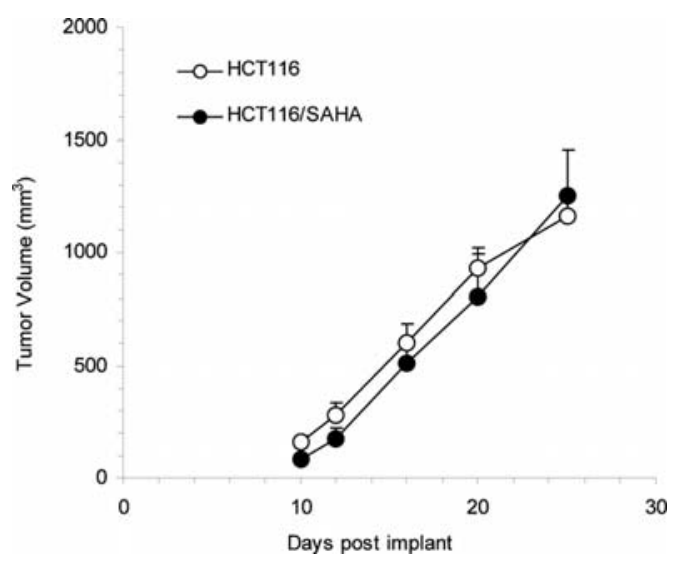

Figure 2. In vivo tumorigenic activity of HCT116/SAHA cells and HCT116 cells. (A) Growth comparison of individual colon tumor xenografts from subcutaneous implants of lines HCT116 (empty circle) and HCT116/ SAHA (filled circle). (B) Growth curve in NOD-SCID mice of colon tumor xenografts from subcutaneous implants of lines HCT116 (empty circle) and HCT116/SAHA (filled circle).

SAHA cells had a reduced growth rate since the duplication time was about $28 \mathrm{~h}$ while HCT116 cells duplicated every $18 \mathrm{~h}$.

HCT116/SAHA cells have a reduced tumorigenic potential in nude mice. Cells $\left(15 \times 10^{6}\right)$ of HCT116 and HCT116/SAHA

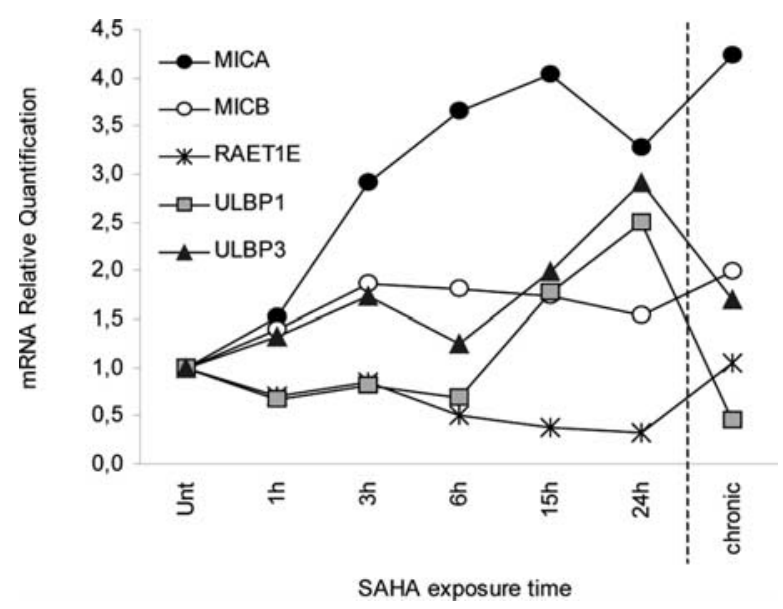

Figure 3. Kinetics of NKG2D ligands following SAHA incubation in HCT116 cells. HCT116 cells were treated with $6 \mu \mathrm{M}$ SAHA for the indicated times. HCT116/SAHA values are indicated with 'chronic'. Total RNAs were reverse-transcribed and amplified by real-time PCR. The mRNA expressions of MICA, MICB, ULBP1, ULBP3 and RAET1E are reported as fold induction values respect to the expression of untreated HCT116 cells (set at 1).

cell line were inoculated s.c. in 3 nude mice and the in vivo growth was observed (Fig. 2A). HCT116 tumor cells grew well and after 40 days from inoculum the tumor volume was around $1500 \mathrm{~mm}^{3}$. HCT116/SAHA tumor cells had a slow growing behavior and a reduced tumor take rate, indeed in 1 over 3 mice the tumor did not growth.

These differences in tumor take and tumor growth were instead not observed when HCT116 and HCT116/SAHA cells were xenografted in NOD/SCID mice (Fig. 2B).

NKG2D ligands are overexpressed in HCT116/SAHA cells. The expression of NKG2D ligands in HCT116/SAHA cells was analysed by real-time PCR. As reported in Fig. 3, MICA and MICB expression was up-regulated in HCT116/SAHA cells. In HCT116/SAHA cells the expression level of MICA and MICB was 4.2- and 2-fold higher than in HCT116 cells, respectively. The other ligands (ULBP1 and ULPB3) were induced over a 24-h SAHA incubation but in the chronic exposure setting they were down-regulated. 
Table II. Clonogenic activity of HCT116/SAHA cells and HCT116 cells in the absence of drug.

\begin{tabular}{|c|c|c|c|c|c|c|c|c|c|}
\hline \multirow[b]{4}{*}{ Tumor lines } & \multicolumn{9}{|c|}{ Cloning efficiency $(\%)$} \\
\hline & \multicolumn{3}{|c|}{700} & \multicolumn{3}{|c|}{4000} & \multicolumn{3}{|c|}{8000 cells/petri dish } \\
\hline & \multicolumn{2}{|c|}{ Colonies no. } & \multirow{2}{*}{$\begin{array}{c}\text { Cloning } \\
\text { efficiency }(\%)\end{array}$} & \multicolumn{2}{|c|}{ Colonies no. } & \multirow{2}{*}{$\begin{array}{c}\text { Cloning } \\
\text { efficiency }(\%)\end{array}$} & \multicolumn{2}{|c|}{ Colonies no. } & \multirow{2}{*}{$\begin{array}{c}\text { Cloning } \\
\text { efficiency }(\%)\end{array}$} \\
\hline & Mean & $\mathrm{SD}$ & & Mean & $\mathrm{SD}$ & & Mean & $\mathrm{SD}$ & \\
\hline HCT116 & 133.0 & 31.6 & 19.0 & n.d. & & n.d. & n.d. & & n.d. \\
\hline HCT116/SAHA & n.d. & & n.d. & 145.3 & 20.6 & 3.6 & 173.0 & 16.3 & 2.2 \\
\hline
\end{tabular}

A different cell number was plated (700, 4000 and 8000 cells/plate) and the number of colonies was counted after 7 days.

Table III. Clonogenic survival of HCT116/SAHA cells and HCT116 cells exposed to anticancer drugs.

\begin{tabular}{lccc}
\hline & \multicolumn{2}{c}{ Cytotoxicity (nM) } & \\
\cline { 2 - 3 } & HCT116 & HCT116/SAHA & IR \\
\hline SAHA & 540 & 2720 & 5.04 \\
Doxorubicin & 14.5 & 2.75 & 0.19 \\
Sabarubicin & 23.5 & 5.30 & 0.23 \\
\hline
\end{tabular}

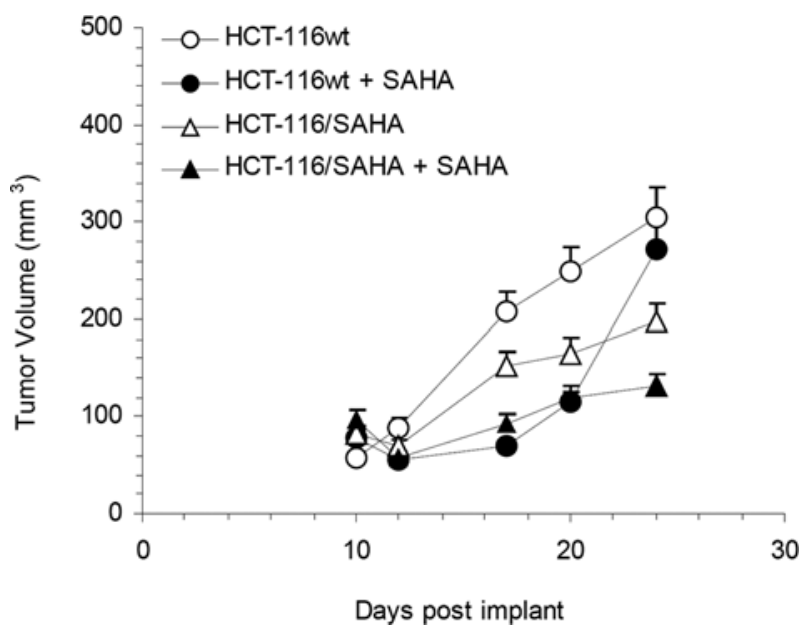

Figure 4. Antitumor activity of SAHA in HCT116 and HCT116/SAHA tumors. Tumor-bearing mice were treated with SAHA at $50 \mathrm{mg} / \mathrm{kg}$ i.v. once daily, 5 days/week, for a total of 10 doses, starting when tumors were $\sim 50 \mathrm{~mm}^{3}$ in volume. The control group was treated with the vehicle. Each point represents the mean volume from 4 tumors \pm SE.

This result correlates with the reduced tumorigenic activity in nude mice since it has been shown that mouse NK cells can induce lysis of human tumor cells (8). Thus, although nude mice are immunodeficient hosts, it is possible that the residual immune system is an important component of the reduced in vivo growth of HCT116/SAHA cells.
HCT116/SAHA cells show a reduced cloning efficiency in vitro. To investigate the proliferative ability of HCT116/ SAHA cells, the cloning efficiency was measured. Clonogenic data revealed that wild-type cell line was able to clone more efficiently than HCT116/SAHA cells (Table II). In particular, HCT116 cells had a cloning efficiency of $19 \%$ while HCT116/SAHA cells had a cloning efficiency of $2 \%$ in the absence of any drugs. Moreover, the shape of the colonies was completely different from those formed by HCT116 cells (data not shown) in agreement with morphological data observed in Fig. 1.

HCT116/SAHA cells maintain SAHA sensitivity in vitro and in vivo. The sensitivity of HCT116/SAHA and HCT116 cells to SAHA was also measured (Table III). In this experimental conditions a low level of resistance is displayed by HCT116/ SAHA cells. In particular, $\mathrm{IC}_{50}$ was 0.54 and $2.7 \mu \mathrm{M}$ for HCT116 and HCT116/SAHA, respectively. HCT116/SAHA cells were instead hypersensitive to two drugs belonging to the chemical class of anthracyclines (Table III). HCT116/ SAHA cells are 5- and 4-fold more sensitive to doxorubicin and sabarubicin, respectively, than HCT116 cells.

Fig. 4 shows the antitumoral activity of SAHA in HCT116 and HCT116/SAHA tumor xenografted in nude mice. The two tumor lines in the absence of any drug confirmed a completely different growth; instead the treated group reached after 2 week-treatment (day 20 post implant in the Figure) the same residual tumor volume. Important to be noted is the difference of growth of HCT116 and HCT116/SAHA tumors after the end of the treatment: indeed a fast and prompt re-growth of HCT116 tumor (full circle) was observed in contrast with a steady-state kinetics of tumor volume in HCT116/SAHA tumors (full triangle).

Gene expression profiling in HCT116/SAHA cells by realtime PCR array. A real-time PCR array for the detection of 84 genes involved in cancer was performed to compare expression profiles of HCT116/SAHA, HCT116 and HCT1 16 cells exposed for $24 \mathrm{~h}$ to SAHA. Data were selected with a threshold of 3-fold-change in the expression (Fig. 5).

As expected, the gene expression profile of HCT116/ SAHA cells was substantially different from that of HCT116 cells. In HCT116/SAHA cells, 15 out of 84 genes were up- 


\begin{tabular}{|c|c|c|c|c|c|c|c|c|c|}
\hline AKT1 & & CDK4 & & IFNA1 & $\mathrm{N}$ & MCAM & & PDGFA & TERT \\
\hline ANGPT1 & $\mathrm{N}$ & CDKN1A & & IFNB1 & $\mathrm{N}$ & MDMR & & PDGFB & TGFB1 \\
\hline ANGPT2 & & CDKN2A & & IGF1 & $\mathrm{N}$ & MET & & PIKR31 & TGFBR1 \\
\hline APAF1 & & CFLAR & & IL8 & & MMP1 & $\mathrm{N}$ & PLAU & THBS1 \\
\hline ATM & & CHEK2 & & ITGA1 & & MMP2 & $N$ & LPAUR & TIMP1 \\
\hline BAD & & COL18A1 & & ITGA2 & & MMP9 & $N$ & PNN & TIMP3 \\
\hline BAX & & E2F1 & & ITGA3 & & MTA1 & & RAF1 & TNF \\
\hline $\mathrm{BCL} 2$ & & ERBB2 & & ITGA4 & $\mathrm{N}$ & MTA2 & & RB1 & TNFRSF10B \\
\hline BCL2L1 & & ETS2 & & ITGAV & & MTSS1 & & S100A4 & TNFRSF1A \\
\hline BRCA1 & & FAS & & ITGB1 & & MYC & & SERPINB5 & TNFRSF25 \\
\hline CASP8 & & FGFR2 & $\mathrm{N}$ & ITGB3 & & NFKB1 & & SERPINE1 & TP53 \\
\hline CCNE1 & & FOS & & ITGB5 & & NFKBIA & & SNCG & TMST1 \\
\hline CDC25A & & GZMA & $\mathrm{N}$ & JUN & & NME1 & & SYK & EPDR1 \\
\hline CDK2 & & HTATIP2 & & MAP2K1 & & NME4 & & TEK & VEGF \\
\hline$x>10$ & & $10>x>5$ & & $5>x>4$ & & $4>x>3$ & & $3>x>2$ & $2>x>1$ \\
\hline$-2<x<-1$ & & $-3<x<-2$ & & $-4<x<-3$ & & $-5<x<-4$ & & $-10<x<-5$ & $x<-10$ \\
\hline
\end{tabular}

Figure 5. Analysis of tumor gene expression in HCT116/SAHA cells by real-time PCR array. The expression of 84 genes involved in cancer are reported as fold induction values respect to the wild-ype HCT116 gene expression. Data were selected with a threshold of fold-change set to 3 . In bold, genes that are selectively regulated into HCT116/SAHA cells (fold induction or down-regulation >3) with respect to HCT116 cells exposed for 24 h to SAHA.

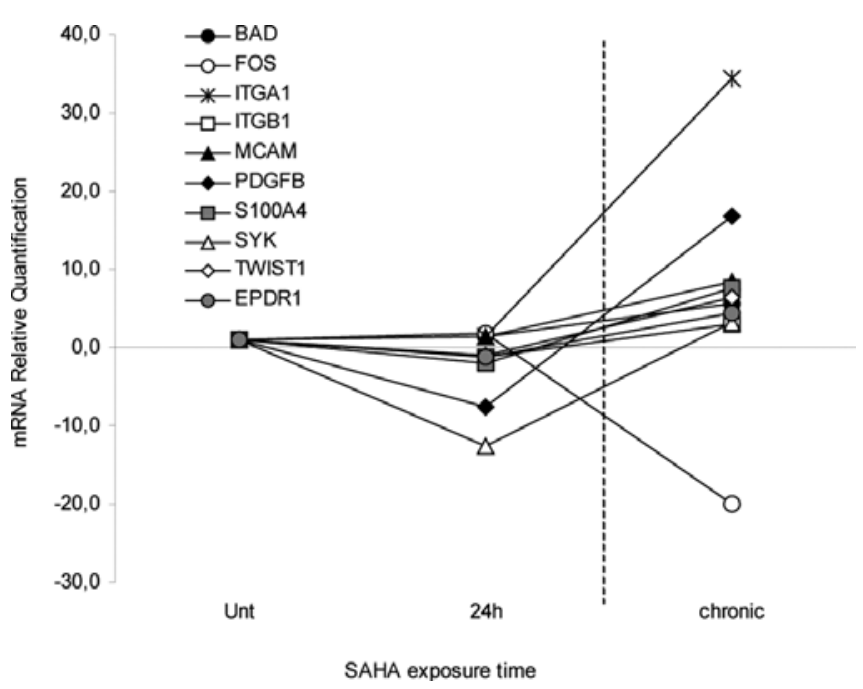

Figure 6. Analysis by real-time PCR of tumor gene expression in HCT116/ SAHA cells and in HCT116 cells treated for $24 \mathrm{~h}$ with $6 \mu \mathrm{M}$ SAHA.

regulated respect to $\mathrm{HCT} 116$ gene expression (the proapoptotic factor BAD, the integrins ITGA1, ITGB1, ITGB3, the melanoma cell adhesion molecule MCAM, the transcriptional factor TWIST1, the putative metastasis suppressor MTSS1, the platelet-derived growth factor PDGFB, the regulatory subunit of (PI)-3 kinase PIKR31, the S100 calcium binding protein A4 S100A4, the inhibitor of urokinase plasminogen activator SERPINE1, the tyrosine kinase SYK, the anti-angiogenic factor thrombospondin THBS1, the interleukin 8 and the ependymin related protein EPDR1) while five genes were repressed (the transcription factors FOS and NFKB1, the synuclein- $\gamma$ SNCG, the telomerase reverse transcriptase TERT and the vascular endothelial growth factor VEGF) in HCT116/SAHA cells.

We focused on genes that were selectively regulated in HCT $116 /$ SAHA cells with respect to HCT116 cells exposed for $24 \mathrm{~h}$ to the drug (Fig. 6). In HCT116/SAHA cells 10 out of 84 genes were selectively regulated in HCT116/SAHA cells and some of them could at least in part justify the different behavior of HCT116/SAHA cells with respect to HCT116 cells.

\section{Discussion}

SAHA is a new anticancer agent belonging to the class of HDACis. After its approval by the US FDA in 2006 for the treatment of cutaneous $T$ cell lymphoma, now SAHA is trying to find its value for the major hematological and solid tumors in more than 40 clinical trials looking for the right drug combinations. Up to now, the poor knowledge of HDAC functions have led to empirical clinical trials and empirical drug combinations. Thus, it is important to add information to direct effective clinical trials. With this aim, we selected HCT116 cells grown in the continuous presence of $6 \mu \mathrm{M} \mathrm{SAHA}$. Drug resistance is the major obstacle of cancer chemotherapy since it leads to treatment failure and fatal consequences for patients. Even after the coming of target-therapy revolution, drug resistance is still a problem and strategies to overcome it are a challenge since the plasticity of cancer cells is due to mutations potentially allowing the survival in any kind of selective pressure; indeed frequently, both in vitro and in the clinical practice, combinations of drugs do not cure cancer because broad spectrum resistance 
is observed. This multidrug resistance is based on a vast array of mechanisms among which there are ABC transporters (9). The HDACi depsipepide has been found to induce P-glycoprotein expression in T-cell lymphoma model and in normal and malignant PBMCs obtained from patients $(10,11)$. These studies are of note since P-glycoprotein transports many agents among which doxorubicin and etoposide and indeed treatment with depsipeptide induced in acute promyelocytic leukemia cells (12) and in colon cancer cells a subsequent resistance to doxorubicin. Moreover, the resistance to depsipeptide is characterised by a very high resistance index (300-900-fold) as usually observed for cytotoxic agents. On the contrary, SAHA, a different chemical class among HDACis, kills both Pglycoprotein-positive and -negative cells (13).

Both the study presented here and also results already published $(14,15)$ demonstrated that, even after prolonged exposure, SAHA can induce only a slight resistance index in HCT116 cells and a collateral sensitivity to anthracyclines. This result is of note and possibly rely on the fact that HDACis have simultaneously many targets, histones and other cellular proteins, and thus the induction of resistance would require many different mutations. Here, we show that HCT116/SAHA cells acquire a completely different shape, a reduced growth rate and that dramatically reduce their ability to form colonies. Moreover, HCT116/SAHA cells engraftment and growth as tumor xenograft in nude mice is reduced respect to HCT116 cells. This striking result might be at least in part due to the reduced growth rate observed in vitro but also to the ability of HDACis to modulate the expression of MHC class I chain related molecules, MICA and MICB, that binds to the activating immunoreceptor NKG2D. Indeed, it has been published that the induction of NKG2D ligand by treatment with HDACis renders leukemic and hepatoma cells more sensitive to NK cytolysis (16-19). The possible involvement of NK population in the reduced growth of HCT116/SAHA in vivo was also suggested by inoculating HCT116/SAHA cells into NOD SCID mice that, differently from nude mice, lack NK function. In this experimental system HCT116 and HCT116/SAHA cells have the same growth rate. Altogether these results show that the chronic exposure to SAHA renders cancer cells less tumorigenic both in vitro and in vivo and strikingly only slightly resistant to the selective agent SAHA.

Additionally, we also observed an interesting collateral sensitivity to anthracyclines whose targets are the enzymes DNA Topoisomerase II (Table III). It is known that HDAC enzymes interact with DNA topoisomerase II $(20,21)$ and that the combination of HDAC inhibitors, added first, and DNA topoisomerase II poisons is synergistic both in vitro (22-25) and in vivo (26). These observations resulted in a phase I clinical trial using valproic acid followed by epirubicin in advanced solid tumors (27) in which responses were seen in heavily pre-treated patients as well as in patients thought to be epirubicin resistant.

Thus, the anthracycline sensitivity showed here suggests that also a chronic use of hydroxamic-based HDACi might induce/restore anthacycline sensitivity.

Finally, a low density PCR array was used to identify which genes, from different transformation and tumori-
Table IV. Expression of genes differentially expressed in HCT116/SAHA cells with respect to HCT116 exposed for $24 \mathrm{~h}$ to SAHA by real-time PCR.

\begin{tabular}{lrr}
\hline Gene & $24 \mathrm{~h}$ & Chronic \\
\hline BAD & 1.4 & 5.6 \\
FOS & 1.8 & -22.2 \\
ITGA1 & 1.4 & 34.5 \\
ITGB1 & -1.3 & 3.1 \\
MCAM & 1.4 & 8.3 \\
PDGFB & -7.8 & 16.8 \\
S100A4 & -1.9 & 7.6 \\
SYK & -12.7 & 3.1 \\
TWIST1 & -1.0 & 6.3 \\
EPDR1 & -1.2 & 4.3 \\
\hline
\end{tabular}

genesis pathways, were regulated in HCT116/SAHA cells. In particular, we tried to distinguish genes involved in the immediate response of cancer cells to SAHA from genes regulated only in cells exposed chronically to SAHA (Table IV). Notably, a differential gene signature was found between HCT116 acutely exposed to SAHA and in HCT116 chronically exposed to SAHA. Some of the genes uniquely modulated in HCT116/SAHA cells might easily explain their reduced tumorigenicity. For example, the strong induction of the tumor suppressor gene SYK correlates with the observed phenotype in HCT116/SAHA cells. SYK is a tyrosine kinase localised in the centrosome that negatively affects mitotic progression $(28,29)$, its expression is lost during disease progression $(30,31)$ and SYK reactivation suppressed invasion property of cancer cells (31). Further studies are needed to define which of the genes are crucial in the definition of HCT116/SAHA cell phenotype.

In summary, cells selected in the presence of an epigenetic drug (SAHA), differently from the selection operated with a cytotoxic agent or targeted agents, are only slightly resistant to selection agent and acquire many unexpected features such as a reduced clonogenic and tumorigenic potential and collateral sensitivity to anthracyclines. Thus, it is possible to speculate that the induction of HDACi resistance in cancer cells, because of the pleitropic activity of $\mathrm{HDACi}$, would require the many different mutations to occur.

\section{References}

1. Lane AA and Chabner B: Histone deacetylase inhibitors in cancer therapy. J Clin Oncol 27: 5459-5468, 2009.

2. Owens J: 2006 drug approvals: finding the niche. Nat Rev Drug Discov 6: 99-101, 2007.

3. Glaser KB: HDAC inhibitors: clinical update and mechanismbased potential. Biochem Pharmacol 74: 659-671, 2007.

4. Botrugno OA, Santoro F and Minucci S: Histone deacetylase inhibitors as a weapon in the arsenal of differentiation therapies of cancer. Cancer Lett 280: 134-144, 2009.

5. Bates SE and Piekartz RL: Histone deacetylase inhibitors in combinations: will preclinical promises be kept? Cancer J 13: $80-83,2007$. 
6. UKCCCR Guidelines for the welfare of Animals in Experimental Neoplasia. Br J Cancer 1: 1-10, 1998.

7. Geran RI, Greenberg NH, MacDonald MM, Schumacher AM and Abbott BJ: Protocols for screening chemical agents and natural products against animal tumors and other biological systems. Cancer Chemother Rep 3: 1-88, 1972.

8. Friese MA, Platten M, Lutz SZ, et al: MICA/NKG2D-mediated immunogene therapy of experimental gliomas. Cancer Res 63: 8996-9006, 2003.

9. Szakács G, Paterson JK, Ludwig JA, Booth-Genthe C and Gottesman MM: Targeting multidrug resistance in cancer. Nat Rev Drug Discov 5: 219-234, 2006.

10. Piekarz RL, Robey RW, Zhan Z, Kayastha G, Abdeldaim AH, Torrico S and Bates SE: T-cell lymphoma as a model for the use of histone deacetylase inhibitors in cancer therapy: impact of depsipeptide on molecular markers, therapeutic targets and mechanisms of resistance. Blood 103: 4636-4643, 2004

11. Robey RW, Zhan Z, Piekarz RL, Kayastha GL, Fojo T and Bates SE: Increased MDR1 expression in normal and malignant peripheral blood mononuclear cells obtained from patients receiving depsipeptide. Clin Cancer Res 12: 1547-1555, 2006

12. Tabe Y, Konopleva M, Contractor R, Munsell M, Shober WD Jin L, Tsutsumi-Ishii Y, Nagaoka I, Igari J and Andreff M: Up-regulation of MDR1 and induction of resisitance by histone deacetylase inhibitor depsipeptide (FK228) and ATRA in acute promyelocytic leukemia cells. Blood 107: 1546-1554, 2006.

13. Peart MJ, Tainton KM, Ruefli AA, Dear AE, Sedelies KA, O'Reilly LA, Waterhouse NJ, Trapani JA and Johnston RW: Novel mechanisms of apoptosis induced by histone deacetylase inhibitors. Cancer Res 63: 4460-4471, 2003.

14. Fedier A, Dedes KJ, Imesch P, Von Buren AO and Fink D: The histone deactetylase inhibitors suberoylanilide hydroxamic (Vorinostat) and valproic acid induce irreversible and MDR-1 independent resistance in human colon cancer cells. Int J Oncol 31: 633-641, 2007

15. Imesch P, Dedes KJ, Furlato M, Fink D and Fedier A: MLH protects from resistance acquisition by the histone deacetylase inhibitor trihcostatin A in colon tumor cells. Int J Oncol 35 631-640, 2009

16. Armeanu S, Bitzer M, Lauer UM, Venturelli S, Pathil A, Krusch M, Kaiser S, Jobst J, Smirnow I, Wagner A, Steinle A and Salih HR: Natural killer cell-mediated lysis of hepatoma cells via specific induction of NKG2D ligands by the histone deacetylase inhibitor sodium valproate. Cancer Res 65 6321-6329, 2005.

17. Skov S, Pedersen MT, Andresen L, Straten PT, Woetmann A and Odum N: Cancer cells become suscetible to natural killer cell killing after exposure to histone deacetylase inhibitors due to glycogen synthase kinase-3-dependent expression of MHC class I-related chain A and B. Cancer Res 65: 1136-11145, 2005.

18. Diermayr S, Himmelreich H, Durovic B, Mathys-Schneeberg A, Siegler U, Langenkamp U, Hofsteenge J, Gratwohl A, Tichelli A, Paluszewska M, Wiktor-Jedrzejczak W, Kalberer CP and Wodnar-Filipowicz: A NKG2D ligand expression in AML increases in response to HDAC inhibitor valproic acid and contributes to allorecognition by NK cell lines with single KIR-HLA-class I specificities. Blood 111: 1428-1436, 2008.
19. Kato N, Tanaka J, Sugita J, Toubai T, Miura Y, Ibata M, Syono $\mathrm{Y}$, Ota $\mathrm{S}$, Kondo T, Asaka $\mathrm{M}$ and Imamura $\mathrm{M}$ : Regulation of the expression of MHC class I-related chain A,B (MICA, MICB) via chromatin remodelling and its impact on the susceptibility of leukemic cells to the cytotoxicity of NKG2D-expressing cells. Leukemia 21: 2103-2108, 2007.

20. Johnson CA, Padget K, Austin CA and Turner BM: Deacetylase activity associates with topoisomerase II and is necessary for etoposide-induced apoptosis. J Biol Chem 276: 4539-4542, 2001.

21. Tsai SC, Valkov N, Yang WM, Gump J, Sullivan D and Seto E: Histone deacetylase interacts directly with DNA topoisomerase II. Nat Genet 26: 349-353, 2000.

22. Kim MS, Blake M, Back JH, Kohlhagen G, Pommier Y and Carrier F: Inhibition of histone deacetylase increases cytotoxicity to anticancer drugs targeting DNA. Cancer Res 63: 7291-7300, 2003

23. Kurz EU, Wilson SE, Leader KB, Sampey BP, Allan WP, Yalowich JC and Kroll DJ: The histone deacetylase inhibitor sodium butyrate induces DNA topoisomerase II $\alpha$ expression and confers hypersensitivity to etoposide in human leukemic cell lines. Mol Cancer Ther 1: 121-131, 2001.

24. Cutts SM, Rephaeli A, Nudelman A, Hmelnitsky I and Phillips DR: Molecular basis for the synergistic interaction of adriamycin with the formaldehyde-releasing prodrug pivaloyloxymethyl butyrate (AN-9). Cancer Res 61: 81948202,2001

25. Marchion DC, Bicaku E, Daud AI, Richon V, Sullivan DM and Münster PN: Sequence-specific potentiation of topoisomerase II inhibitors by the histone deacetylase inhibitor suberoylanilide hydroxamic acid. J Cell Biochem 92: 223-237, 2004.

26. Marchion DC, Bicaku E, Daud AI, Sullivan DM and Münster PN: In vivo synergy between topoisomerase II and histone deacetylase inhibitors: predictive correlates. Mol Cancer Ther 4: 1993-2000, 2005.

27. Münster PN, Marchion DC, Bicaku E, Schmitt M, Lee JH, De Conti R, Simon G, Fishman M, Minton S, Garrett C, Chiappori A, Lush R, Sullivan DM and Daud AI: Phase I trial of histone deacetylase inhibition by valproic acid followed by the topoisomerase II inhibitor epirubicin in advanced solid tumors: a clinical and translation study. J Clin Oncol 25: 1879-1985, 2007.

28. Zyss D, Montcourrier $\mathrm{P}$, Vidal $\mathrm{B}$, Anguille $\mathrm{C}$, Mérezègue $\mathrm{F}$, Sahuquet A, Mangeat PH and Coopman PJ: The Syk tyrosine kinase localizes to the centrosomes and negatively effects mitotic progression. Cancer Res 65: 10872-10880, 2005.

29. Coopman PJ and Mueller SC: The Syk tyrosine kinase: a new negative regulator in tumor growth and progression. Cancer Lett 241: 159-173, 2006.

30. Wang L, Devarajan E, He J, Reddy SP and Dai JL: Transcription repressor activity of spleen tyrosine kinase mediates breast tumor suppression. Cancer Res 65: 10289-10297, 2005.

31. Yuan Y, Liu H, Sahin A and Dai JL: Reactivation of SYK expression by inhibition of DNA methylation suppresses breast cancer cell invasiveness. Int J Cancer 113: 654-659, 2005. 